\title{
Assessing landslide movements in volcanic islands using near-shore marine geophysical data: south Pico island, Azores
}

\author{
Neil C. Mitchell • Rui Quartau • José Madeira
}

Received: 7 September 2010 /Accepted: 18 August 2011 / Published online: 27 September 2011

(C) Springer-Verlag 2011

\begin{abstract}
Marine geophysical data from around the submarine flanks of volcanic islands can potentially help to resolve whether large-scale instability of an edifice has been geologically recently active. We use geophysical data to investigate part of the coast of Pico Island of the Azores where, above sea-level, a major slump of Topo volcano has been interpreted previously from arcuate escarpments and a rugged irregular topography seaward of them. Multibeam echo-sounder data collected offshore of this feature show remarkably little evidence for slump fault movements in the island's submarine slope. Mid-slope benches, like those associated with the Hilina Slump of Kilauea, are absent. The high-resolution data extends onto the island's shelf, allowing us to evaluate evidence for continuing activity there. In particular, as the shelf's rock platform will have been last modified by surf erosion during the postglacial period of sea-level transgression, it provides a reference surface of intermediate age $(7-19 \mathrm{ka})$ that can potentially reveal whether any movements occurred in pre-historic
\end{abstract}

Editorial responsibility: B. van Wyk de Vries

N. C. Mitchell $(\bowtie)$

School of Earth, Atmospheric and Planetary Sciences,

University of Manchester,

Manchester M13 9PL, UK

e-mail: neil.mitchell@manchester.ac.uk

\section{R. Quartau}

Unidade de Geologia Marinha-Laboratório Nacional de Energia

e Geologia I.P., Estrada da Portela, Zambujal,

Alfragide,

2721-866 Amadora, Portugal

\section{J. Madeira}

Faculdade de Ciências, Departamento de Geologia, and Laboratório de Tectonofísica e Tectónica Experimental/Instituto Dom Luiz (Laboratório Associado), Universidade de Lisboa, Lisboa, Portugal times. Where the arcuate escarpments are continued offshore, the modern seabed shows no bathymetric evidence for active faults where the shelf rock platform crops out in the multibeam data. Elsewhere, mobile shelf sediments could be disguising evidence for active faulting so we examined boomer profiles able to image the rock platform beneath them. The data reveal a platform that is steep $\left(6.6^{\circ}\right)$ compared with the dips of platforms that we have studied previously around the coast of adjacent Faial Island and steeper than the platform outside the proposed slump. This suggests that it was created by coastal erosion over a shorter period and hence is consistent with a younger age of the coastline. As with the multibeam data, where escarpments are continued offshore onto the shelf, the rock surface imaged with these boomer data also shows no clear evidence of major slump-related fault displacements. This study therefore illustrates how high-resolution boomer seismic and multibeam data could usefully contribute to hazard assessment of volcanic islands, by helping to evaluate areas with no historical movements. Explanations to reconcile the onshore and offshore data here are also put forward.

Keywords Volcano collapse $\cdot$ Slump $\cdot$ Hazards $\cdot$ Coastal erosion

\section{Introduction}

Identifying and dating collapse structures is important for hazard assessment of volcanoes as well as for understanding this significant geological process. Before sonar datasets began to be collected, the incidence of lateral collapses (landslides) of volcanic ocean islands was considered uncertain by some researchers and for some locations 